\title{
Management of Rathke's Cleft Cysts: About Three Observations
}

\author{
Bouali Sofiene1*, Badri Mohamed2, Boubaker Adnene1, Ben Said Imed1, Bouhoula Asma1, \\ Zemmel Ihsen'2, Jemel Hafedh ${ }^{1}$ \\ ${ }^{1}$ Department of Neurosurgery, National Institute of Neurology Mongi Ben Hmida, Tunis, Tunisia \\ ${ }^{2}$ Department of Neurosurgery CTGB, Ben Arous, Faculty of Medicine, University OF Tunis El Manar, Tunis, Tunisia \\ Email: sofienebouali@hotmail.fr
}

Received 21 July 2014; revised 21 August 2014; accepted 10 September 2014

Copyright (C) 2014 by authors and Scientific Research Publishing Inc.

This work is licensed under the Creative Commons Attribution International License (CC BY). http://creativecommons.org/licenses/by/4.0/

(c) (i) Open Access

\begin{abstract}
Rathke cleft cysts are benign sellar lesions that are generally asymptomatic. Rathke cleft cyst can enlarge and become symptomatic. Surgical therapy is the mainstay of treatment for symptomatic RCC. The optimal surgical strategy remains debatable. We report our experience with this lesion and we discuss the advantages and disadvantages of each technique through a literature review.
\end{abstract}

\section{Keywords}

Rathke Cleft Cyst, Transsphenoidal Surgery, Magnetic Resonance Imaging

\section{Introduction}

Symptomatic Rathke cleft cysts (RCC) account for approximately 6\% - 10\% of sellar and suprasellar lesions in neurosurgical series [1] [2]. Surgical therapy is the mainstay of treatment for symptomatic RCC [1]. The optimal surgical strategy remains debatable.

We report our experience with this lesion and we discuss the advantages and disadvantages of each technique through a literature review.

\section{Case Report}

\section{CASE 1:}

A 45-year-old male complained from hypogonadisme for 1 year. Examination showed a bitemporal quadranopsy with scarcity of hair. Laboratory tests showed a panhypopituitarism. Brain MRI disclosed an intra and su-

\footnotetext{
${ }^{*}$ Corresponding author.

How to cite this paper: Sofiene, B., Mohamed, B., Adnene, B., Imed, B.S., Asma, B., Ihsen, Z. and Hafedh, J. (2014) Management of Rathke's Cleft Cysts: About Three Observations. Open Journal of Modern Neurosurgery, 4, $169-172$. 
prasellar cystic lesion, hypointense on T1-weighted images and, hyperintense on T2 with surrounding enhancement, causing slight deformation of the optic chiasm (Figure 1). A complete removal was performed by a fronto-pterional approach and histological examination confirmed the diagnosis of Rathke cleft cyst.

The follow up during 3 years was marked by the persistence of endocrine disorders.

CASE 2:

A 36-year-old male complained from significant progressive reduction of visuel acuity upon 18 months. Examination showed a bitemporal hemianopsy with optic atrophy. The preoperative MRI study revealed a round, suprasellar and intrasphenoidal lesion (Figure 2). A partial resection with evacuation of the cyst content was performed via a transphenoidal approach. Histological examination concluded for a Rathke's cleft cyst. The postoperative course was complicated by the appearance of rhinorrhea. The patient underwent later on a second surgery through a fronto-pterional route which allowed the achievement of complete removal of the cyst and cure of the CSF leackage.

CASE 3:

A 14-year-old teenager was admitted for growth retardation and delayed puberty, with a short stature and absence of secondary sexual characters at examination. Brain MRI showed an extensive intra-and suprasellar lesion which enhanced discretely in peripheral surrounding (Figure 3). The lesion was removed through a right fronto-pterional approach without any significant complications.
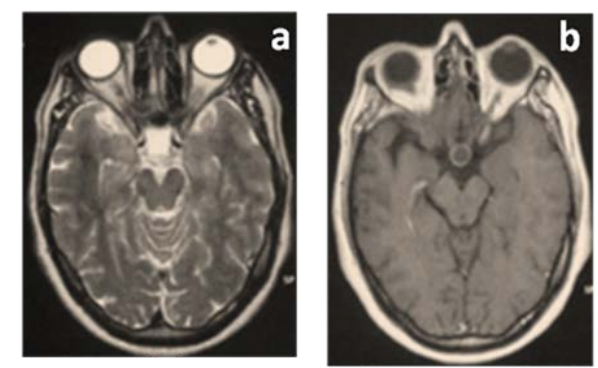

Figure 1. Brain MRI showing an intra and suprasellar cystic lesion, hyperintense on T2-weighted images (a) with surrounding enhancement (b), causing slight deformation of the optic chiasm.
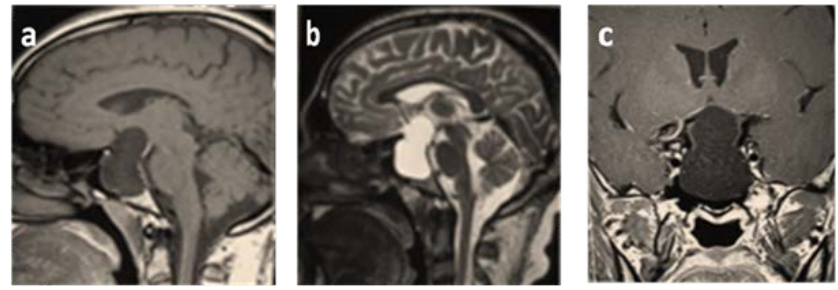

Figure 2. Preoperative brain MRI, T1 weighted sagittal (a); T2 weighted sagittal (b) and coronal (c) after contrast images showing a round, suprasellar and intrasphenoidal lesion, hypointense to brain on the native T1 and hyperintense T2-weighted images with moderate enhancement of the outer border, causing a slight deformation of the optic chiasm.
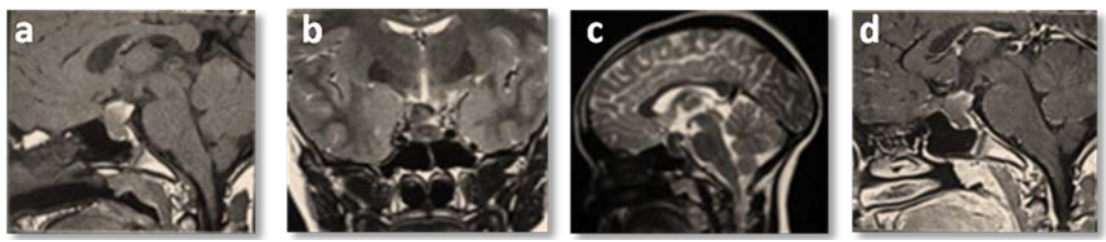

Figure 3. preoperative brain MRI, T1 weighted sagittal (a); T2 weighted coronal (b) and sagittal (c); sagittal (d) after contrast images showing an extensive intra-and suprasellar lesion which enhanced discretely in peripheral surrounding. 
Anatomopathology affirmed the diagnosis of Rathke’s cleft cyst.

The follow up during 2 years was uneventful.

\section{Discussion}

Rathke's cleft cysts (RCC) are thought to be non-obliterated remnants of the primitive craniopharyngeal duct [1]. They are benign lesions that may expand by accumulation of cyst fluid and then become symptomatic by compression of the surrounding structures [2] [3]. Asymptomatic RCCs are a relatively common finding in routine autopsies, whereas symptomatic RCCs are rare [2]-[4]. The introduction of MRI has improved the diagnosis of such cysts preoperatively or even incidentally [5] [6].

RCCs require surgery only when they are symptomatic [5] [6]. A partial resection of the single-cell layered epithelial wall with evacuation of the cyst content is often sufficient to yield good results with very rare recurrences [5]-[8]. As only cyst decompression is necessary, the transsphenoidal route is the recommended approach for intrasellar RCCs, because of the lower risk of surgical mortality and morbidity when compared to the transcranial approach [6] [8] [9]. Indeed, the occurrence of new endocrine deficits is less at about $6 \%$ to $7 \%$ and visual improvement results are better with this approach [5]-[9]. However, the risk of postoperative complications such as rhinorrhea, meningitis, sinusitis and nasal septal perforation is higher [9] [10]. Our only patient who was treated by this approach developped rhinorrhea.

Undoubtedly, the transsphenoidal endoscopic approach has similar efficacy to standard approaches with further lower morbdity as reported in recent papers [5] [8].

Because only cyst decompression without removal of the capsule is the goal, this modality of treatment can be acceptable in RCC [8] [9].

When the cyst has a large suprasellar extension or is located entirely in the suprasellar region, or when a craniopharyngioma is initially suspected, a fronto-temporal craniotomy is then recommended [1] [3] [9].

\section{Conclusion}

Symptomatic RCC requires surgical treatment. TSS is the safest and most effective route. Simple drainage of the cyst with biopsy of the wall has been the treatment goal for many years. The optimal surgical strategy remains debatable. Longer follow-up and larger surgical series will help to establish the optimal treatment approach.

\section{Conflicts of Interest}

All authors declare no conflict of interest.

\section{References}

[1] Kleinschmidt-DeMasters, B.K., Lillehei, K.O. and Steam, J.C. (1995) The Pathologic, Surgical, and MR Spectrum of Rathke Cleft Cysts. Surgical Neurology, 44, 19-27. http://dx.doi.org/10.1016/0090-3019(95)00144-1

[2] Cohan, P., Foulad, A., Esposito, F., et al. (2004) Symptomatic Rathke’s Cleft Cysts: A Report of 24 Cases. Journal of Endocrinological Investigation, 27, 943-948. http://dx.doi.org/10.1007/BF03347537

[3] Babu, R., Back, A.G., Komisarow, J.M., et al. (2013) Symptomatic Rathke’s Cleft Cyst with a Co-Existing Pituitary Tumor; Brief Review of the Literature. Asian Journal of Neurosurgery, 8, 183-187. http://dx.doi.org/10.4103/1793-5482.125662

[4] Nishioka, H., Haraoka, J., Izawa, H. and Ikeda, Y. (2006) Headaches Associated with Rathke’s Cleft Cyst. Headache, 46, 1580-1586. http://dx.doi.org/10.1111/j.1526-4610.2006.00539.x

[5] Ross, D.A., Norman, D. and Wilson, C.B. (1992) Radiologic Characteristics and Results of Surgical Management of Rathke's Cysts in 43 Patients. Neurosurgery, 30, 173-178; Discussion, 178-179. http://dx.doi.org/10.1227/00006123-199202000-00004

[6] Nishioka, H., Haraoka, J., Izawa, H. and Ikeda, Y. (2006) Magnetic Resonance Imaging, Clinical Manifestations, and Management of Rathke’s Cleft Cyst. Clinical Endocrinology (Oxford), 64, 184-188. http://dx.doi.org/10.1111/j.1365-2265.2006.02446.x

[7] Chuang, C.C., Chen, Y.L., Jung, S.M. and Pai, P.C. (2010) A Giant Retroclival Rathke’s Cleft Cyst. Journal of Clinical Neuroscience, 17, 1189-1191. http://dx.doi.org/10.1016/j.jocn.2009.12.017

[8] El-Mahdy, W. and Powell, M. (1998) Transsphenoidal Management of 28 Symptomatic Rathke’s Cleft Cysts, with 
Special Reference to Visual and Hormonal Recovery. Neurosurgery, 42, 7-16; $16-7$.

[9] Han, S.J., Rolston, J.D., Jahangiri, A. and Aghi, M.K. (2013) Rathke’s Cleft Cysts: Review of Natural History and Surgical Outcomes. J Neurooncol., 117, 197-203.

[10] Janeczko, C., McHugh, J., Rawluk, D., et al. (2009) Hypophysitis Secondary To ruptured Rathke’s Cyst Mimicking Neurosarcoidosis. Journal of Clinical Neuroscience, 16, 599-600. http://dx.doi.org/10.1016/j.jocn.2008.04.031

\section{Abbreviations}

MRI: magnetic resonance imaging

RCC: symptomatic Rathke cleft 
Scientific Research Publishing (SCIRP) is one of the largest Open Access journal publishers. It is currently publishing more than 200 open access, online, peer-reviewed journals covering a wide range of academic disciplines. SCIRP serves the worldwide academic communities and contributes to the progress and application of science with its publication.

Other selected journals from SCIRP are listed as below. Submit your manuscript to us via either submit@scirp.org or Online Submission Portal.
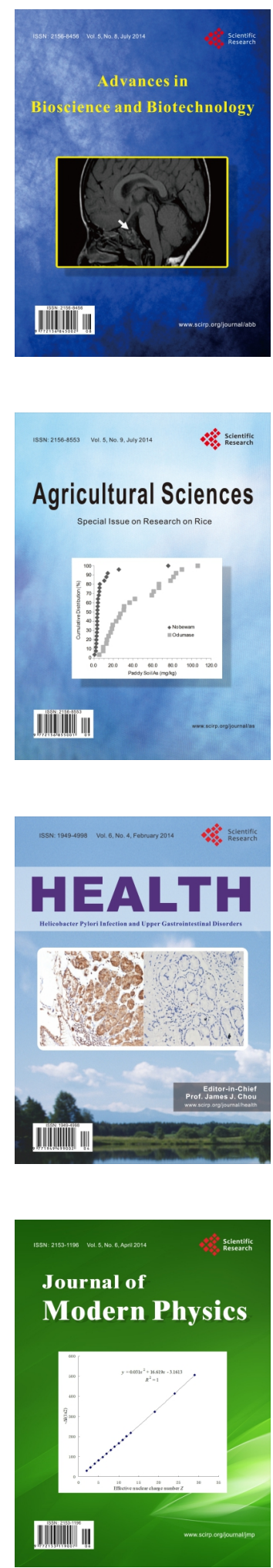
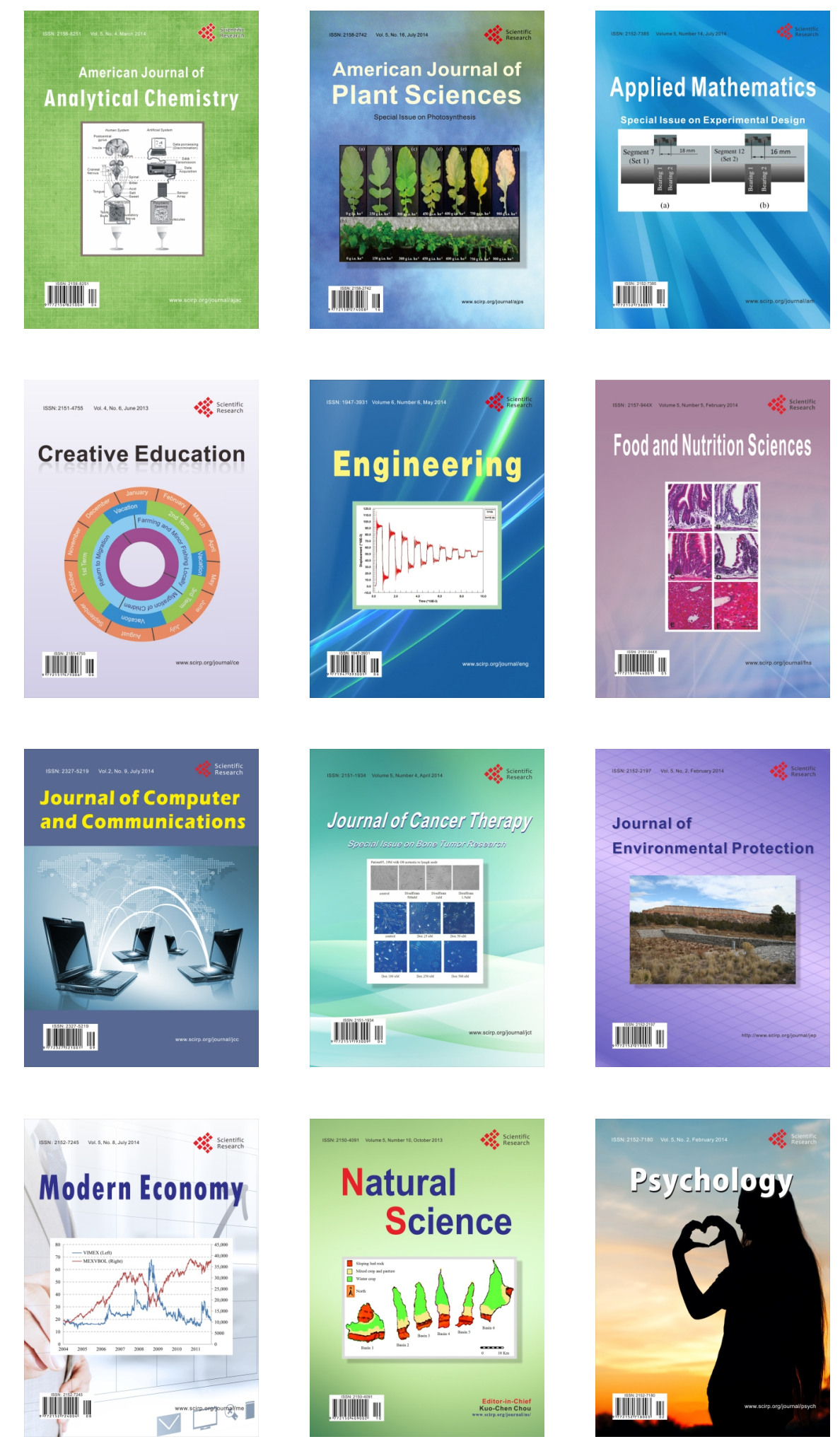